\title{
The relevance of sagittal radiographic parameters
}

\author{
Catherine A. Miller, MD, ${ }^{1}$ Kai-Ming Fu, MD, ${ }^{2}$ and Praveen V. Mummaneni, MD1 \\ ${ }^{1}$ Department of Neurological Surgery, University of California, San Francisco, California; and 'Department of Neurological \\ Surgery, Weill Cornell Medical College, New York, New York
}

A DULT spinal deformity (ASD) causes significant pain and disability, affecting the quality of life of those who suffer from it. ASD encompasses a heterogeneous group of patients with varying degrees of deformity and disability. ${ }^{1}$ Historically, evaluation and treatment of ASD focused on the coronal plane. Efforts to determine the causes of pain and disability led to a focus on sagittal plane deformity. Deformity surgeons now assess the sagittal plane and pelvic parameters in standard decision-making for patients with ASD. However, ASD is multifactorial and the pain and disability of some patients may not be related solely to sagittal plane deformity. Identifying those patients who may not need an extensive reconstruction in the sagittal plane is of great interest in expanding treatment opportunities, including less-invasive options.

Faraj et al. ${ }^{2}$ present a study that evaluates the correlation between sagittal radiographic parameters and pretreatment patient-reported health-related quality of life (HRQOL) measures in patients with symptomatic de novo degenerative lumbar scoliosis (DNDLS). This is a retrospective analysis of patients with ASD selected from a multicenter prospectively collected database. Seventy-four patients met the study criteria for symptomatic DNDLS: age $\geq 55$ years, lumbar Cobb angle (CA) $10^{\circ}-55^{\circ}$, apex of curve located in the lumbar spine (L1-5), and Scoliosis Research Society (SRS) subtotal domain score $\leq 4.0$ or Oswestry Disability Index (ODI) $\geq 20$. Patients with double curves, a history of juvenile or adolescent idiopathic scoliosis, neuromuscular spinal abnormalities, previous spinal surgery, or metabolic spinal pathology were excluded from this study.

Overall, these investigators found several weak but significant correlations between preoperative HRQOL and radiographic parameters. Pelvic tilt (PT) had a weak correlation with SRS pain domain and numeric rating scale (NRS) back pain $(r=0.282$ and -0.260 , respectively). An additional correlation was found between sagittal ver- tebral axis (SVA) and ODI $(\mathrm{r}=0.296)$. The coronal CA had several weak correlations: NRS back pain $(r=0.295)$, SRS pain domain $(r=-0.309)$, SRS self-image domain $(r$ $=-0.308)$, and the SRS subtotal $(\mathrm{r}=-0.306)$. The two parameters that account for pelvic compensation, T1-pelvic angle (TPA) and global tilt (GT), did not have any correlations with HRQOL. Other sagittal parameters such as pelvic incidence (PI), lumbar lordosis (LL), PI-LL mismatch, and thoracic kyphosis were not found to have any correlations. Interestingly, when patients were stratified according to age ( $<70$ vs $\geq 70$ years old), there was a significant difference in GT, TPA, and SVA but no difference in HRQOL. The results of this study differ from past reports demonstrating the significance of sagittal plane deformity as a negative driver of quality of life. ${ }^{1,5}$

A potential shortcoming of this study is the relatively small number of patients included in the severe sagittal plane deformity category. Inclusion of more of these patients may have resulted in findings similar to past reports. ${ }^{3}$ In addition, the definition of de novo degenerative scoliosis in this report may include those with mild undetected adolescent deformity that progressed.

It is clear that ASD is a multifactorial disease and not all patients can be treated in a similar fashion. The focus on sagittal plane deformity is important but may lead to some patients undergoing more-invasive reconstructions, when potentially a candidate for short-segment open decompression/fusion or a minimally invasive surgical technique. Identifying those patients for whom sagittal plane deformity is not the main driver of pain and disability (such as septuagenarians with primarily leg pain and without back pain) will perhaps allow more treatment options in the future. ${ }^{4}$

The authors are commended for their work. This publication contributes to the growing ASD literature to better understand the subset of patients with DNDLS and how they differ from other subgroups.

https://thejns.org/doi/abs/10.3171/2017.9.SPINE17857 


\section{References}

1. Bess J, Line B, Fu KM, McCarthy I, Lafage V, Schwab F, et al: The health impact of symptomatic adult spinal deformity: comparison of deformity types to united states population norms and chronic diseases. Spine (Phila Pa 1976) 41:224-233, 2016

2. Faraj SSA, De Kleuver M, Vila-Casademunt A, Holewijn RM, Obeid I, Acaroğlu E, et al: Sagittal radiographic parameters demonstrate weak correlations with pretreatment patient-reported health-related quality of life measures in symptomatic de novo degenerative lumbar scoliosis: a European multicenter analysis. J Neurosurg Spine [epub ahead of print March 23, 2018. DOI: 10.3171/2017.8.SPINE161266]

3. Mundis GM Jr, Turner JD, Deverin V, Uribe JS, Nunley P, Mummaneni P, et al: A critical analysis of sagittal plane deformity correction with minimally invasive adult spinal deformity surgery: a 2-year follow-up study. Spine Deform 5:265-271, 2017

4. Park P, Okonkwo DO, Nguyen S, Mundis GM Jr, Than $\mathrm{KD}$, Deviren V, et al: Can a minimal clinically important difference be achieved in elderly patients with adult spinal deformity who undergo minimally invasive spinal surgery? World Neurosurg 86:168-172, 2016

5. Than KD, Park P, Fu KM, Nguyen S, Wang MY, Chou D, et al: Clinical and radiographic parameters associated with best versus worst clinical outcomes in minimally invasive spinal deformity surgery. J Neurosurg Spine 25:21-25, 2016

\section{Disclosures}

Dr. Fu reports being a consultant to SI Bone. Dr. Mummaneni reports being a consultant to DePuy Spine and Stryker; having direct stock ownership in Spinicity/ISD; receiving support of non-study-related clinical or research effort from the NREF; receiving honoraria from AOSpine and Globus; and receiving royalties from DePuy Spine, Thieme, and Springer.

\section{Response}

\section{Sayf S. A. Faraj, BSc, ${ }^{1}$ Roderick M. Holewijn, MD, ${ }^{2}$ Marinus de Kleuver, MD, PhD, ${ }^{1}$ and Ferran Pellisé, MD, PhD ${ }^{3}$}

${ }^{1}$ Department of Orthopedics, Radboud University Medical Center, Nijmegen, The Netherlands; ' $D$ Department of Orthopaedic Surgery, VU University Medical Center, Amsterdam, The Netherlands; and ${ }^{3}$ Spine Surgery Unit, Hospital Universitari Vall d'Hebron, Barcelona, Spain

We appreciate the comments provided by Drs. Miller, $\mathrm{Fu}$, and Mummaneni. ASD covers a broad spectrum of spine disorders that can occur during adulthood. The optimal surgical techniques for correction of ASD, including restoration of the sagittal plane, are well defined. ${ }^{4}$ However, the etiology and clinical and radiographic characteristics of the diverse spinal deformities included in the broad spectrum of ASD can be significantly different from one another. ${ }^{1}$ Consequently, etiology could be an important contributing factor to the variation found in the strength of previously established correlations between radiographic parameters and HRQOL.

Our goal was to understand the impact of the sagittal plane on pretreatment patient-reported HRQOL restricted to DNDLS, rather than the heterogeneous entity of ASD. We agree with the comment provided by Dr. Miller et al. that discrimination between DNDLS and other forms of ASD (e.g., the adult form of idiopathic scoliosis) is not always simple. ${ }^{3}$ In order to acquire a specific DNDLS patient population, previously reported distinguishing characteristics were implemented as inclusion criteria (e.g., age $\geq 55$ years, lumbar curve location, and curve severity). ${ }^{1,2}$ We found no clinically relevant association between pretreatment patient-reported HRQOL and spinopelvic parameters in patients suffering from DNDLS. We hypothesize that in this specific subtype of ASD, an underlying diagnosis (such as canal stenosis) could be more important in driving suboptimal HRQOL rather than spinopelvic parameters. We agree with Dr. Miller and colleagues that it is of paramount importance to identify patients who may not need extensive reconstruction in the sagittal plane. Identification of patients for whom sagittal malalignment is not the main cause of pain and driver of disability may lead to better patient selection for less-invasive treatment options. Notably, it remains unknown whether postoperative sagittal parameters are associated with HRQOL scores in DNDLS. It may be that postoperative HRQOL is driven by yet other factors. ${ }^{5}$ A further study specifically focused on the relationship between postoperative radiographic parameters and HRQOL scores is therefore suggested.

\section{References}

1. Aebi M: The adult scoliosis. Eur Spine J 14:925-948, 2005

2. Grubb SA, Lipscomb HJ: Diagnostic findings in painful adult scoliosis. Spine (Phila Pa 1976) 17:518-527, 1992

3. Guler UO, Yuksel S, Yakici S, Domingo-Sabat M, Pellise F, Pérez-Grueso FJS, et al: Analysis of the reliability of surgeons' ability to differentiate between idiopathic and degenerative spinal deformity in adults radiologically. What descriptive parameters help them decide? Eur Spine J 25:2401-2407, 2016

4. Schwab FJ, Blondel B, Bess S, Hostin R, Shaffrey CI, Smith JS, et al: Radiographical spinopelvic parameters and disability in the setting of adult spinal deformity: a prospective multicenter analysis. Spine (Phila Pa 1976) 38:E803-E812, 2013

5. Takemoto M, Boissière L, Vital JM, Pellisé F, Perez-Grueso FJS, Kleinstück F, et al: Are sagittal spinopelvic radiographic parameters significantly associated with quality of life of adult spinal deformity patients? Multivariate linear regression analyses for pre-operative and short-term post-operative health-related quality of life. Eur Spine J 26:2176-2186, 2017 